\title{
Tethered cord: natural history, surgical outcome and risk for Chiari malformation 1 (CM1)
}

\author{
A review of 110 detethering
}

\author{
Laura Grazia Valentini - Giorgio Selvaggio • \\ Sergio Visintini · Alessandra Erbetta • \\ Vidmer Scaioli · Carlo Lazzaro Solero
}

Published online: 16 September 2011

(C) The Author(s) 2011. This article is published with open access at Springerlink.com

\begin{abstract}
The surgical results of this series of occult spina bifida seem better than the natural history registered in the long pre-operative period in terms of neurological deterioration. The major contribution to this result is attributed to neurophysiological monitoring that lowers the risks of permanent damage and increases the percentage of effective detethering. The present series of TCS, due to conus and filar lipoma, documents that $\mathrm{CM} 1$ is a really rare association occurring in less than $6 \%$ of the patients, despite the low position of conus. The detethering procedure did not influence the tonsillar position, thus excluding the correlation between the tethering and the tonsillar descent. The genetic alteration documented in a girl reinforces the hypothesis of a rare complex polymaformative picture deserving multiple procedures according to the prevailing clinical symptoms.
\end{abstract}

Keywords Chiari 1 malformation · Children · Tethered cord $\cdot$ Detethering

L. G. Valentini $(\varangle) \cdot$ S. Visintini · C. L. Solero

Department of Neurosurgery, Fondazione Istituto Neurologico

"Carlo Besta", Via Celoria 11, 20133 Milan, Italy

e-mail: 1valentini@istituto-besta.it

G. Selvaggio

Department of Pediatric Surgery, Ospedale Pediatrico

"Vittore Buzzi", Milan, Italy

A. Erbetta

Services of Neuroradiology, Fondazione Istituto Neurologico

"Carlo Besta", Milan, Italy

V. Scaioli

Services of Neurophysiology, Fondazione Istituto Neurologico

"Carlo Besta", Milan, Italy

\section{Introduction}

It has been recently suggested that CM1 in some cases may caused by tethered cord with a traction mechanism [1]; this may be the case also if the conus is located in a normal position due to a reduced elasticity of the filum, thick or lipomatous, and the name for this condition is occult tethered cord [10]. As a consequence of this hypothesis, the filum section has been proposed for the treatment of CM1 in a selected group of patients by some authors [5] and in very case of CM1 and scoliosis by others [7].

This pathogenesis has been deeply criticized for two reasons: while in open spina bifida the CM type 2 in a very frequent association, the association of occult spina bifida and CM1 is so rare to be anecdotal; secondly there are some experimental studies that showed no variation in the tonsillar position after detethering in the cadaver [8].

The clinical picture of tethering is caused by ischemia of the lower conus due to 'traction' of the spinal cord occurring with growth and flexion [6,7]; this mechanism leads to motor deficits and spasms, sensory problems, and urodynamic and anorectal abnormalities; later on, orthopedic deformations may also occur due to the strength disequilibrium on feet and calves. The tethered cord syndrome (TCS) associated with CM1, characterized by a conus positioned lower than the endplate of L2, as well as the occult conus tethering (traction due to a tight anelastic filum with conus at a normal level [8]; if it exists, is expected to cause the cauda equina symptoms by the same mechanism [4].

The aim of the present study is to look the Chiari problem from below by a "caudorostral" perspective: we reviewed our series of patients operated on for a "real tethering" searching for an associated tonsillar herniation to define the incidence of CM1 in tethered cord. 
Recently we tried to understand better the role of the two malformations on symptoms; so we performed the detethering by first to see if the simple filum sectioning somehow influences the tonsillar position, so restoring the CSF circulation with a benefit on Chiari related symptoms and syringomyelia.

\section{Case series and surgical treatment}

The present study concerns 110 patients operated on for a "real tethering" (TCS) between 1990 and 2008 at the Fondazione Istituto Neurologico "Carlo Besta" (FINCB) of Milan, Italy.

All the patients were submitted to a whole MR examination both before and after the surgery to document the tonsillar position and the presence of a syrinx. The conus level was L2L3 in 55 cases, L4 in 41 and L5 or lower in 14.

A terminal Syringomyelia was documented in $30 \%$, a cutaneous stigmata was observed in $86 \%$ of the cases, with a dermal sinus in $20 \%$. All patients' neurological examination were scored by the Hoffman Scale [2] from diagnosis to follow-up to have comparable data.

Despite the clear signs for diagnosis, all the patients were symptomatic at the time of surgery and $74 \%$ presented progressive deterioration during the long pre-operative period. In fact, the mean time span occurred between diagnosis and surgery was longer than 5 years.

Before being operated, all the patients underwent urodynamic testing with cystometrograms and renal ultrasound. Post-operative urodynamic tests were repeated within the first year after the surgery and later on, if they were abnormal.

The steps of surgery were: resection of the subcutaneous lipoma and of the dermal sinus, laminar exposure, extended at least one space cranially than the first non-schisic segment, laminotomy performed by high speed drill, exposition the intact dural sac, opening of the dura under optic magnification, separation of the intradural lipoma from the lateral and caudal dural adhesion and from neural tissue under EMG-monitoring control, near-complete lipoma removal, sectioning of the tight filum, suture of the placode, positioning of a dural graft to prevent retethering and fibrin glue in order to try and reduce CSF leaks, and fixation of the laminotomic flap.

A CSF collection, deserving surgical revision, occurred in 18 cases and infection in 2 cases; none of these complications caused permanent morbidity.

\section{Results}

By the described procedure detethering was obtained in the great majority of the cases, except five cases (4\%), all performed without EMG intraoperative monitoring. The recurrent surgeries and chaotic lipomas had higher risk of failed detethering. The intraoperative cranial migration of the conus was registered only recently; it was described in 18 cases.

The scored neurological outcome at diagnosis, at surgery, at discharge and at long-term follow-up is summarized in Fig. 1. Transient post-operative deterioration occurred in 11 cases, while permanent post-operative surgery-related deterioration was observed in $5(4 \%)$ cases of conus lipomas; this percentage reduced to zero with intraoperative EMG monitoring.

At a mean follow-up longer than 5 years, late deterioration was observed up to now in four cases, in two cases due to a presacral meningocele, in the other three due to a retethering; the global percentage of late deterioration was $3.5 \%$.

Symptomatic CM1 associated to TCS was observed in six cases, while asymptomatic low lying tonsils (LLT) in two. The global percentage of associated TCS and tonsillar descent was $7 \%$ in this large series.

The two cases of LLT regressed after detethering. Of the symptomatic CM1: in one case the craniovertebral decompression (CVD) was performed at the same time of dethethering with good outcome; in another case, initially symptomatic for CM1, the CVD was performed with good results on bulbar signs, but it was followed 18 months later by a detethering for the progression of a syrinx; the results were good after the second operation; in two cases with mild tonsillar migration the clinical picture stabilized after detethering, with no need for CVD, while in the remaining two CVD had to be performed 1 year after the detethering, to treat progressive syrinx formation and occurrence of bulbar signs; in no case, a cranial migration of the tonsils was observed after detethering.

One of these children affected by both CM1 and TCS, a 4-year-old girl had, beside the CM1 with basilar invagination and TCS due to a filar lipoma, right hand polidattily, a kidney malformation, a morsus inversus and a vesicoureteral reflux. A sub-telomeric deletion of 11 chromosomes was found at the genetic study.

\section{Discussion and conclusions}

This cases series reflects the changes in the timing of diagnosis and surgery along the years in Italy: up to mid1990s, all the cases that were proposed for neurosurgery only when deeply symptomatic; afterwards some asymptomatic case was identified; due to the fear of causing adjunctive deficits our policy was to operate all the symptomatic cases and all the filar lipomas, due to their low risk of post-surgical deterioration. 


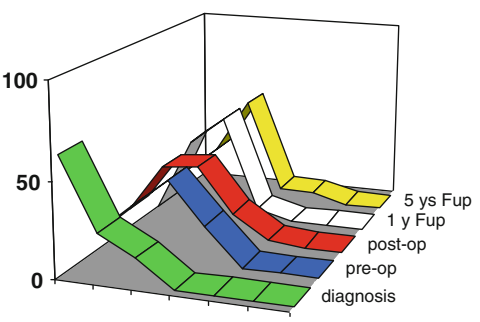

GRADE: FUNCTIONAL GRADING SCALE by Hoffman et al, 1985 [2]

0 No significant neurological, orthopaedic or urological problems Reflex changes and/or sensory deficits

1 Minimal weakness and/or muscle wasting and/or foot deformity, affecting only one leg without significantly disturbing one's walk. Normal bladder and sphincter function

2 Neurogenic bladder alone, or combined with minimal weakness of one leg; or intact bladder function with minimal weakness affecting both legs

3 Moderate to severe weakness of one leg, causing problems with one's walk, with or without neurogenic bladder or minimal weakness of both legs combined with neurogenic bladder

4 Severe paraparesis requiring aids for walking, with or without neurogenic bladder

5 Inability to walk

Fig. 1 Neurological picture evolution

On the contrary all the asymptomatic conus medullaris lipomas were strictly followed by serial urodynamic testing during the first year of life. In this way, an urodynamic deterioration was observed in 12 children in the first 18 months of life; obviously these data have no statistic value, because the test has been applied only recently, but a deterioration was discovered in more than an half of the tested children. All the cases were operated soon after the urodynamic variation, with normalization of the bladder function.

The global rate of neurological deterioration before surgery in this series was higher than $50 \%$ in the long preoperative period; this may be assumed as the rate of deterioration of symptomatic lipoma in their "natural history". On the contrary, the risk of early and late permanent post-surgical deterioration was low $(4+3 \%)$, as well as the percentage of "failed" detethering (4\%); globally, surgery failed in $11 \%$ of the cases; a result quite better than the natural history.

In our experience, intraoperative multichannel EMG monitoring can be carried out and requires minimal variations in anesthetic regimens. With this method, it is possible to better identify the neural structures of complex malformations, reducing the risk of surgical damage and incomplete detethering, so improving furtherly the results of surgery. Retethering is a well-known cause of late deterioration [3]; its percentage was low in the present series.

In relation to $\mathrm{CM} 1$, the tonsillar descent was observed in a very low percentage of the cases $(7 \%)$, despite the very low dislocation of the conus medullaris in this large series of occult spina bifida. These data increase the uncertainty that the downward traction plays some role generating
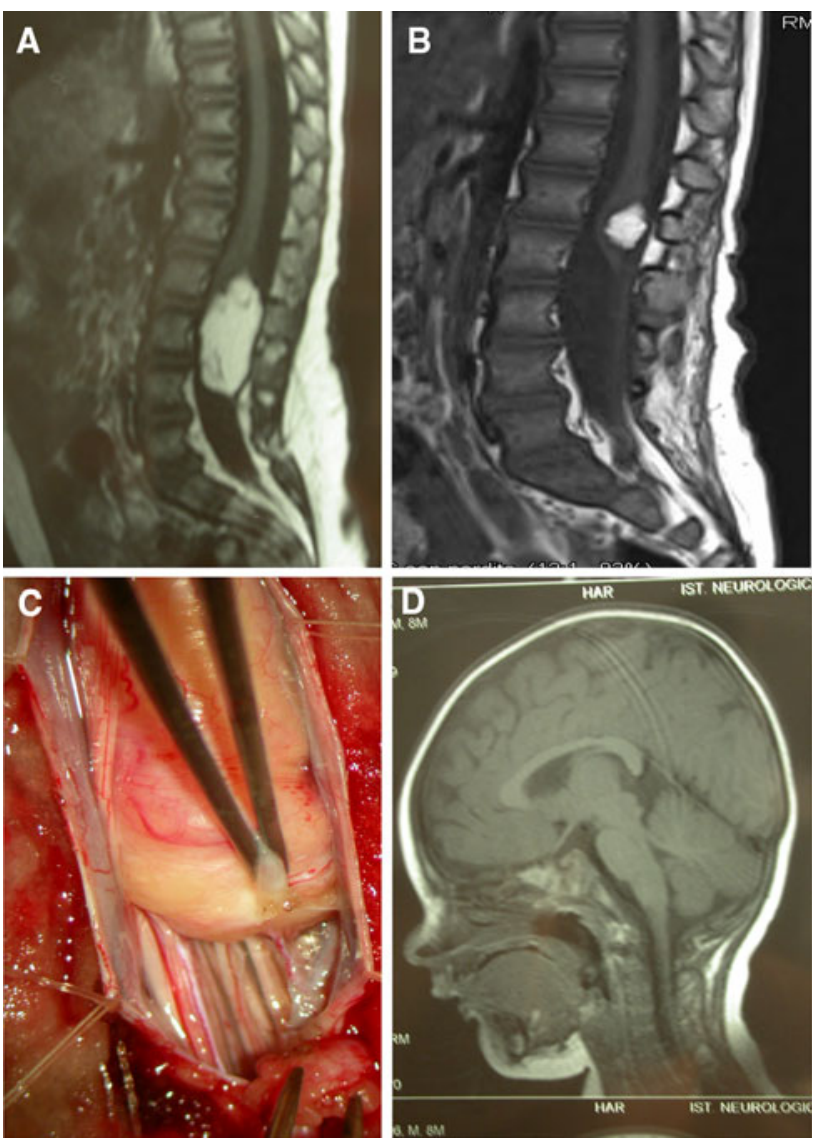

Fig. 2 Cranial migration of the conus medullaris. a Preoperative RMI of RR, 9-month-old male, harboring a typical caudal conus lipoma: despite the relevant traction of the conus (positioned at L4 level before surgery), documented intraoperatively (c) and solved by surgery, as documented by the significant cranial migration (b) toward L2, the tonsillar position (d) was normal preoperatively and remained the same after surgery

CM1 [9]. This absence of correlation is confirmed also by the pre-operative normal position of the tonsils in all the cases with a documented intraoperative traction of the conus. No variation of the tonsilar position was obseved at MRI, despite the clear cut post-operative cranial migration of the conus (Fig. 2).

In our opinion, both the genetic alteration found in one girl and the results of surgery on the coexisting malformations that needed separate surgery for different symptoms, orients towards the genetic origin of the rare cases of associated CM1 and TCS, rather than a simple mechanic correlation between the two.

Conflict of interest The authors declare that there is no actual or potential conflict of interest in relation to this article.

Open Access This article is distributed under the terms of the Creative Commons Attribution Noncommercial License which permits any noncommercial use, distribution, and reproduction in any medium, provided the original author(s) and source are credited. 


\section{References}

1. Abel TJ, Chowdhary A, Gabikian P, Ellenbogen RG, Avellino AM (2006) Acquired Chiari malformation associated with a fatty terminal filum. J Neurosurg 105(4):329-332

2. Hoffman HJ, Taecholarn C, Hendrick EB, Humphreys RP (1985) Management of lipomyelomeningoceles: experience at the Hospital for Sick Children, Toronto. J. Pediatr Neurosci 1:3-13

3. Kang J, Lee K, Jeun S, Lee I, Kim M (2003) Role of surgery for maintaining urological function and prevention of retethering in the treatment of lypomeningomyelocele: experience recorded in 75 lipomeningomyelocele patients. Childs Nerv Syst 19:23-29

4. Milhorat TH, Bolognese PA, Nishikawa M, Francomano CA, McDobbell NB, Roonprapunt C, Kula RW (2009) Association of Chiari malformation type I and tethered cord syndrome: preliminary results of sectioning filum terminale. Surg Neurol 72:20-35
5. Milhorat TH, Nishikawa M, Kula RW, Dlugacz YD (2010) Mechanisms of cerebellar tonsil herniation in patients with Chiari malformations as a guide to clinical management. Acta Neurochir, mancano pgg e volume

6. Pang D (1991) Tethered cord syndrome: newer concepts. In: Neurosurgery Update. McGraw-Hill, USA, pp 336-344

7. Royo-Salvador MB, Sole-Llenas J, Dumenech JM et al (2005) Results of the section of the filum terminale in 20 patients with syringomyelia, scoliosis and Chiari Malformation. Acta Neuroch (Wien) 147:515-523

8. Tubbs RS, Oakes WJ (2004) Can the conus medullaris in a normal position be tethered? Neurol Res 26:727-731

9. Tubbs RS, Loukas M, Shoja MM et al (2007) Observations at the craniocervical junction with simultaneous caudal traction of the spinal cord. CNS 26:727-731

10. Warder DE, Oakes WJ (1993) Tethered cord syndrome and the conus in a normal position. Neurosurgery 33:374-378 